\title{
Synthesis and Biological Activities of Myomodulin A and Its Analogs
}

\author{
Nam Gyu Park*
}

Department of Biotechnology, Fisheries Science College, Pukyong National University, Busan 608-737, Korea

Received December 21, 2011 /Revised January 20, 2012 / Accepted January 25, 2012

\begin{abstract}
In this study, we focused on myomoduline A (MMA) released from the central nervous system of Aplysia kurodai. The primary structure of MMA is Pro-Met-Ser-Met-Leu-Arg-Leu-NH $\mathrm{NH}_{2}$. This peptide is the same as that of the myomodulin family peptide found in other mollusks. The purified MMA showed a modulating activity of phasic contraction on the anterior byssus retractor muscle (ABRM) of Mytilus edulis. In order to study the relationship between the structure and biological activity of MMA, we synthesized MMA, Des[Pro $\left.{ }^{1}\right]$-MMA, Des[Pro $\left.{ }^{1}, \operatorname{Met}^{2}\right]-M M A, \operatorname{Des}\left[\operatorname{Pro}^{1}, \operatorname{Met}^{2}, \operatorname{Ser}^{3}\right]-M M A$, and MME. The amino acid sequences of Des[Pro $\left.{ }^{1}\right]-M M A, D e s\left[\operatorname{Pro}^{1}, \mathrm{Met}^{2}\right]-M M A$, and Des[Pro $\left.{ }^{1}, \mathrm{Met}^{2}, \mathrm{Ser}^{3}\right]$ MMA were Met-Ser-Met-Leu-Arg-Leu- $\mathrm{NH}_{2}$, Ser-Met-Leu-Arg-Leu-NH ${ }_{2}$, and Met-Leu-Arg-Leu-NH2, respectively. MMA and synthetic peptides were tested on ABRM in $M$. edulis as well as muscle preparations in Achatina fulica. At $1 \times 10^{-8} \mathrm{M}$ or lower, MMA showed a potentiating effect on phasic contraction of the ABRM, but this peptide had an inhibitory effect at $1 \times 10^{-6} \mathrm{M}$ or higher. Both MMA and its analogs stimulated a contractile response on the crop and a relaxed catch-relaxing response on the penial retractor muscle of $A$. fulica. These results suggest that Met-Leu-Arg-Leu- $\mathrm{NH}_{2}$ in MMA is the minimum structure required for the regulation of the contraction of ABRM, as well as the reproductive and digestive activities of mollusks.
\end{abstract}

Key words : Myomodulin A, analog, penial retractor muscle, anterior byssus retractor muscle

\section{서 론}

생체 내에 존재하는 신경시스템이 정상적으로 작동하기 위 해서 이들이 분비하는 신경성 펩타이드의 조절 작용이 매우 중요한 역할을 한다고 알려져 있다[1,15]. 신경성펩타이드는 뉴런으로부터 분비되는 signalling molecular로 보통 4-30개 정도의 아미노산으로 구성된 물질이다. 이들은 중추신경계와 말초신경계에 넓게 분포하고 있으며, 일반적으로 생체 내에서 호르몬 혹은 비 호르몬으로서 평활근의 운동조절, 혈관의 수 축 및 이완, 통증전달 및 혈압조절 등의 역할을 담당하고 있는 neuromodulator 및 neurotransmitter이다[3,38,45]. 이들 신경 성 펩타이드들 중의 하나인 myomodulins $(\mathrm{MMs})$ 의 정제 및 다양한 생리활성에 관한 연구가 활발히 진행되고 있다 [7,8,14,41]. MMs중에서는 MMA가 군소 (Aplysia californica)의 B16-accessory radula closer (ARC) muscle로부터 처음 발견 되었으며 $[8,12]$, 그 후 계속해서 $\mathrm{MMB}$ 와 $\mathrm{MMC}$ 및 $\mathrm{MME}$ 가 정 제되었다[13,12,31]. 뿐만 아니라 동일한 종의 ARC muscle로 부터 $\mathrm{MMC}, \mathrm{MMD}, \mathrm{MME}$ 및 $\mathrm{MMF}$ 가 정제되었고[2], $\mathrm{MMG}$, $\mathrm{MMH}$ 및 $\mathrm{MMI}$ 는 $\mathrm{cDNA}$ 연구에 의해 일차구조 서열이 밝혀졌 다[28,30]. 현재까지 군소로부터 9종류의 $\mathrm{MMs}$ (MMA, MMB, $\mathrm{MMC}, \mathrm{MMD}, \mathrm{MME}, \mathrm{MMF}, \mathrm{MMG}, \mathrm{MMH}$ 및 $\mathrm{MMI}$ 가 알려져 있으며, MM-like 펩타이드들이 연체동물 및 환형동물로부터

\section{*Corresponding author}

Tel : +82-51-629-5867, Fax : +82-51-629-5863

E-mail : ngpark@pknu.ac.kr
정 제되었다. 연체동물로는 Fusinus [22], Rapana [17], Helix pomatia [21], H. aspersa [18], Mercenaria 및 Helix peptide [25], Lymnaea [36,37,41], Mytilis [20]이며, 환형동물로는 Perinereis [40] 및 Hirudo [43]이다.

Table 1에 그들의 일차구조를 나타내었다. MMs는 7-8 잔기 의 아미노산으로 구성된 펩타이드이며, C-말단에 Met-Leu$\mathrm{Arg}-\mathrm{Leu}-\mathrm{NH}_{2}$ 의 공통영역을 가지고 있다. 모든 $\mathrm{MMs}$ 들은 $1 \times 10^{-8} \mathrm{M}$ 에서 군소의 $\mathrm{ARC}$ muscle에 대해 수축을 증가시켰지 만, 7 가지 $\mathrm{MMs}$ (MMA 및 $\mathrm{MMD}-\mathrm{MMI}$ )는 $1 \times 10^{-9}-1 \times 10^{-8}$ $\mathrm{M}$ 에서 수축을 감소시키는 활성을 나타내었다[44]. 그리고, $\mathrm{MMs}$ 들은 군소의 motor neuron의 이완활성 속도를 활성화 시키는 동시에 $\mathrm{K}^{+}$및 $\mathrm{Ca}^{2+}$ current를 활성화 시켰다[2]. 한편, ARC motor neuron B16 및 abdominal neuron L10에서 MMA 는 $\mathrm{MMB}$ 보다 약 6배 높은 농도로 존재한다고 보고되었다[13]. 특히, 다양한 신경성 펩타이드들은 군소에서 섭식행동에 관련 된 신경에서 발생하는 전기적 수축반응에 대한 modulator로 서 작용한다고 알려져 있으며 $[4,8-10,12,13,27,35]$, 음식물을 먹 는 과정에 사용되는 $\mathrm{ARC}$ 근육으로부터 정제된 $\mathrm{MMA}$ 는 섭식 행동의 과정에 관여하는 물질 중의 하나이다[6,11]. $\mathrm{MMs}$ 은 Lymnaea의 penis retractor muscle의 수축 및 전기적으로 유도 된 수축의 이완 속도를 증대시키는 작용을 지닌다[26,41]. 면역 조직학적 연구에 의하면 $\mathrm{MMs}$ 들은 군소의 신경절, 말초신경, 시각, 섭식, 소화, 심장 및 생식기계에서도 반응을 나타내었다 [29]. 뿐만 아니라 면역조직반응은 메뚜기, 게 및 쥐의 신경조 직에서도 반응을 나타내었으며 $[4,39,42], \mathrm{MMA}$ 는 메뚜기의 평 
Table 1. Myomodulin A and related peptides: amino acid sequence of peptides from several species of molusks

\begin{tabular}{|c|c|c|c|c|c|c|c|c|c|c|}
\hline \multirow{2}{*}{$\frac{\text { Spcies }}{\text { Aplysia }}$} & \multirow{2}{*}{$\begin{array}{l}\text { Name } \\
\text { MMA }\end{array}$} & \multicolumn{8}{|c|}{ Amino acid } & \multirow{2}{*}{$\frac{\text { Reference }}{12,23,30}$} \\
\hline & & & $\mathrm{P}$ & $\mathrm{M}$ & $\mathrm{S}$ & $\mathrm{M}$ & $\mathrm{L}$ & $\mathrm{R}$ & $\mathrm{L}$ amide & \\
\hline & $\mathrm{MMB}$ & G & $S$ & Y & $\mathrm{R}$ & $\mathrm{M}$ & M & $\mathrm{R}$ & $\mathrm{L}$ amide & 13,30 \\
\hline & $\mathrm{MMC}$ & & G & $\mathrm{W}$ & $S$ & M & $\mathrm{L}$ & $\mathrm{R}$ & $\mathrm{L}$ amide & 2,23 \\
\hline & MMD & & G & $\mathrm{L}$ & $S$ & M & $\mathrm{L}$ & $\mathrm{R}$ & $\mathrm{L}$ amide & 30 \\
\hline & MME & & G & $\mathrm{L}$ & $Q$ & M & $\mathrm{L}$ & $\mathrm{R}$ & $\mathrm{L}$ amide & 2,23 \\
\hline & MMF & & $S$ & $\mathrm{~L}$ & $\mathrm{~N}$ & $\mathrm{M}$ & $\mathrm{L}$ & $\mathrm{R}$ & $\mathrm{L}$ amide & 30 \\
\hline & MMG & & $\mathrm{T}$ & $\mathrm{L}$ & $\mathrm{S}$ & M & $\mathrm{L}$ & $\mathrm{R}$ & $\mathrm{L}$ amide & 30 \\
\hline & $\mathrm{MMH}$ & & G & $\mathrm{L}$ & $\mathrm{H}$ & M & $\mathrm{L}$ & $\mathrm{R}$ & $\mathrm{L}$ amide & 30 \\
\hline & MMI & & $S$ & $\mathrm{~L}$ & $S$ & M & $\mathrm{L}$ & $\mathrm{R}$ & $\mathrm{L}$ amide & 30 \\
\hline \multirow[t]{4}{*}{ Lymnaea stagnalis } & & & $\mathrm{P}$ & M & $S$ & $\mathrm{M}$ & $\mathrm{L}$ & $\mathrm{R}$ & $\mathrm{L}$ amide & \multirow{4}{*}{26} \\
\hline & & & $S$ & $\mathrm{~L}$ & $S$ & M & $\mathrm{L}$ & $\mathrm{R}$ & $\mathrm{L}$ amide & \\
\hline & & & $S$ & M & $S$ & $\mathrm{M}$ & $\mathrm{L}$ & $\mathrm{R}$ & $\mathrm{L}$ amide & \\
\hline & & & G & $\mathrm{L}$ & Q & $\mathrm{M}$ & $\mathrm{L}$ & $\mathrm{R}$ & $\mathrm{L}$ amide & \\
\hline \multirow[t]{5}{*}{ Helix } & & & $\mathrm{P}$ & $\mathrm{M}$ & $\mathrm{S}$ & $\mathrm{M}$ & $\mathrm{L}$ & $\mathrm{R}$ & $\mathrm{L}$ amide & 21 \\
\hline & & & S & $\mathrm{L}$ & G & M & $\mathrm{L}$ & $\mathrm{R}$ & $\mathrm{L}$ amide & 21 \\
\hline & & & G & $\mathrm{L}$ & $\mathrm{N}$ & $\mathrm{M}$ & $\mathrm{L}$ & $\mathrm{R}$ & $\mathrm{L}$ amide & 21 \\
\hline & & & pQ & $\mathrm{L}$ & $S$ & $\mathrm{M}$ & $\mathrm{L}$ & $\mathrm{R}$ & $\mathrm{L}$ amide & 21 \\
\hline & & & $\mathrm{pQ}$ & $\mathrm{L}$ & $\mathrm{P}$ & $\mathrm{M}$ & $\mathrm{L}$ & $\mathrm{R}$ & $\mathrm{L}$ amide & 21 \\
\hline \multirow[t]{2}{*}{ Fusinus thomasiana } & & & $\mathrm{P}$ & M & $\mathrm{S}$ & $\mathrm{M}$ & $\mathrm{L}$ & $\mathrm{R}$ & $\mathrm{L}$ amide & 22 \\
\hline & & & $\mathrm{P}$ & M & $\mathrm{N}$ & M & $\mathrm{L}$ & $\mathrm{R}$ & $\mathrm{L}$ amide & 22 \\
\hline Rapana thomasiana & & & $\mathrm{P}$ & M & G & M & $\mathrm{L}$ & $\mathrm{R}$ & $\mathrm{L}$ amide & 17 \\
\hline Mytilus edulis & CARP & & A & M & $\mathrm{P}$ & $\mathrm{M}$ & $\mathrm{L}$ & $\mathrm{R}$ & $\mathrm{L}$ amide & 20 \\
\hline \multicolumn{11}{|l|}{ Annelid } \\
\hline Perinereis & & & A & M & G & $\mathrm{M}$ & $\mathrm{L}$ & $\mathrm{R}$ & $\mathrm{M}$ amide & 40 \\
\hline Hirudo & & & G & $\mathrm{M}$ & G & A & $\mathrm{L}$ & $\mathrm{R}$ & $\mathrm{L}$ amide & 43 \\
\hline
\end{tabular}

활근에 대해서도 수축반응을 보였다[14,34].

최근에 국내에 서식하고 있는 군소(Aplysia kurodar)의 중추 신경계의 추출물로부터 $\mathrm{MMA}$ 및 $\mathrm{MME}$ 가 정제되었다[23]. 본 연구에서는 군소로부터 정제한 $\mathrm{MMA}$ 의 구조 및 활성에 관한 상관관계를 알아보기 위해 $\mathrm{MMA}$ 와 $\mathrm{MMA}$ 의 유도체 및 $\mathrm{MME}$ 를 합성하였다. 또한 이들 물질을 사용하여 진주담치의 $\mathrm{ABRM}$, 아프리카 큰 달팽이의 penial retractor muscle과 소낭 (crop), 불가사리의 dorsal retractor muscle (DRM), 먹장어의 intestine의 smooth muscle, 메추리의 직장(rectum) 및 귀뚜라 미의 소낭에 대한 수축과 이완 반응을 조사하였다.

\section{재료 및 방법}

\section{일반시약}

Sep-Pak Vac $\mathrm{C}_{18}$ cartridge는 Waters사(Waters associates, Miliford, MA, USA)에서, 정제에 사용한 Sephadex G-25 (fine)는 Pharmasia (LKB Biotechnology, Uppsala, Sweden)에
서, 그리고 펩타이드들을 합성하기 위해 Fmoc-NH-PAL Resin (0.55 mmol/g) 및 Fmoc-amino acid는 Advanced Chem Tech (Louisville KY, USA)에서 구입하였다. HPLC-grade용 $\mathrm{H}_{2} \mathrm{O}$ 와 $\mathrm{CH}_{3} \mathrm{CN}$ 은 TEDIA (Ohio, USA)에서 각각 구입하였으며, 그 밖 의 시약은 특급품을 사용하였다.

\section{실험동물}

평활근 수축 및 이완 활성을 측정하기 위해서 아프리카 큰 달팽이(Achatina fulica)의 소낭과 penial retractor muscle, 진주 담치(Mytilus edulis)의 anterior byssus retractor muscle (ABRM), 불가사리(Asterina pectinifera)의 dorsal retractor muscle (DRM), 먹장어(Eptatretus burgeri)의 intestine의 smooth muscle, 메추리(Coturnix japonica)의 직장(rectum) 및 귀뚜라미(Gryllidae bimaculatas)의 소낭을 사용하였다.

\section{진주담치의 $\mathrm{ABRM}$ 에 대한 조절활성}

진주담치의 좌우 패각을 열고, 면실을 이용하여 $\mathrm{ABRM}$ 을 
길이가 약 $1 \mathrm{~cm}$ 가 되도록 윗부분과 아랫부분을 묶은 다음 적출하였다. 적출한 $\mathrm{ABRM}$ 은 인공해수로 채워진 $2 \mathrm{ml}$ 의 반 응조에 고정시켰다. $55 \mathrm{mM} \mathrm{Mg}^{2+}$ 인공해수(ASW)의 조성은 다음과 같다: $(\mathrm{mM}) \mathrm{NaCl} 445 \mathrm{mM}, \mathrm{MgCl}_{2} \cdot 6 \mathrm{H}_{2} \mathrm{O} 55 \mathrm{mM}$, $\mathrm{CaCl}_{2} \cdot 2 \mathrm{H}_{2} \mathrm{O} 10 \mathrm{mM}, \mathrm{KCl} 10 \mathrm{mM}$, Tris- $\mathrm{HCl}(\mathrm{pH}$ 7.8) 10. 준 비한 $\mathrm{ABRM}$ 의 아래쪽 부분을 반응조의 지지대에 고정시키 고 윗부분을 physiograph (NEC-Sanei, Tokyo, Japan)의 transducer에 연결하여 $5 \mathrm{~g}$ 의 장력을 걸었으며, 반복적인 전 기자극 $(23 \mathrm{~V}, 3 \mathrm{msec}, 50 \mathrm{~Hz})$ 을 하여 각 분획에 대해 활성여 부를 측정하였다. Phasic contraction은 10 분 간격으로 행하 였으며, 각 시료 용액은 phasic contraction의 8 분 전에 적용 하였다. Acetylcholine (Ach)에 의한 catch-tension에서 합성 펩타이드들의 이완활성을 측정하기 위해 $\mathrm{ABRM}$ 에 농도 의 존적으로 투여하여 그 변화를 관찰하였다. $10^{-5} \mathrm{M}$ 의 $\mathrm{Ach}$ 는 20 분 간격으로 2 분간 $\mathrm{ABRM}$ 에 적용시킨 후, 근육은 정상 $\mathrm{ASW}$ 로 세정하고 반복적인 전기 자극으로 근육을 자극하여 활성화시켰다. 그런 다음 펩타이드를 농도 의존적으로 투여 하여 실험하였다. 수축 및 이완활성에 대한 모든 실험은 실 온 $\left(23^{\circ} \mathrm{C}\right)$ 에서 행하였다.

\section{달팽이 소낭에 대한 조절 활성}

달팽이의 껍질을 벗긴 다음, 가슴을 절개하여 소낭의 윗 부분과 아래 부분에서 약 $0.5 \mathrm{~cm}$ 씩 떨어진 부분에서 $3-4 \mathrm{~cm}$ 의 크기로 재빨리 적출하였다. 적출한 소낭은 면실을 이용 하여 10-15 mm의 길이로 아래와 위를 묶은 후 실온에서 Ringer용액이 담긴 반응조에 고정시켰다. Ringer 용액의 조 성은 다음과 같다: $(\mathrm{mM}) \mathrm{NaCl} 120, \mathrm{KCl} 4, \mathrm{CaCl}_{2} \cdot 2 \mathrm{H}_{2} \mathrm{O} 0.9$, $\mathrm{MgSO}_{4} \cdot 7 \mathrm{H}_{2} \mathrm{O} 2.5, \mathrm{NaHCO}_{3} 18, \mathrm{NaH}_{2} \mathrm{PO}_{4}$ 4.2. 적출한 소낭 의 아래쪽을 반응조의 지지대에 고정시키고 위쪽은 isomatric transducer에 연결하였다. 이후 $2 \mathrm{~g}$ 의 장력이 주어지 도록 1.5 시간 동안 안정화시켰다. 이때 15 분 간격으로 buffer 를 교체해 주면서 $95 \% \mathrm{O}_{2}$ 와 $5 \% \mathrm{CO}_{2}$ 로 혼합된 가스를 지속 적으로 제공하였다. Tension $2 \mathrm{~g}$ 이 유지된 후, $1 \times 10^{-3} \mathrm{M}$ Ach을 15 분 간격으로 3 회 투여하여 활성화 시켰다. 이후 준 비된 peptide성 약물을 non-cumulative 방법으로 농도 의존 적으로 투여하였다.

\section{달팽이의 penial retractor muscle의 이완 활성}

달팽이의 껍질을 벗긴 다음, 가슴을 절개하고 penial retractor muscle을 면실을 이용하여 10-15 mm의 길이로 아랫부 분과 윗부분을 묶은 후 실온에서 Ringer용액이 담긴 반응조에 고정시켰다. 적출한 penial retractor muscle의 아래쪽을 반응 조의 지지대에 고정시키고 위쪽은 isomatric transducer에 연 결하였으며, 달팽이 소낭에 사용한 같은 용액과 방법으로 활 성을 측정하였다.

\section{불가사리 DRM에 대한 수축 활성}

불가사리의 eye spot을 제거한 후 배면과 복면을 분리하여 배면을 뒤집으면, 5 개 팔을 따라 중앙을 가로지르는 $\mathrm{DRM}$ 을 발견할 수 있다. 이 muscle을 메스로 분리한 후, $20 \mathrm{~mm}$ 정도의 단편으로 만든다. 모든 과정은 $55 \mathrm{mM} \mathrm{Mg}^{2+} \mathrm{ASW}$ 하에서 행하 였다. 준비된 DRM은 아래쪽은 $2 \mathrm{ml}$ 의 반응조의 지지대에 고 정시키고, 위쪽은 isometric transducer에 연결하여 resting tension이 $1.0 \mathrm{~g}$ 이 되도록 30 분간 평형화시켰다. 조직의 tension이 $1.0 \mathrm{~g}$ 이 유지되면 $10^{-5} \mathrm{M}$ 의 $\mathrm{Ach}$ 을 투여하여 근육을 활 성화시켰다. 시료들은 주입한 후 수축활성을 physiograph로 측정하였다.

\section{먹장어의 장관(intestine) 에 대한 수축활성}

장관의 표본을 만들기 위해 배측부를 항문 쪽으로 절개하였 다. 그 후 식도로부터 $3-4 \mathrm{~cm}$ 떨어진 부위를 2-3 cm 길이로 재빨리 적출하였다. 절취한 장관의 결체조직을 제거하고, 5 $\mathrm{mm}$ 정도의 장관 단편을 만들어 $2 \mathrm{ml}$ 반응조에 고정시켰다. 모든 과정은 $55 \mathrm{mM} \mathrm{Mg}^{2+} \mathrm{ASW}$ 하에서 행하였다. 준비된 장관 은 아래쪽은 $2 \mathrm{ml}$ 의 반응조에 고정시키고 위쪽은 physiography system의 isometric transducer에 연결하여 $1.5 \mathrm{~g}$ 의 장 력을 준 뒤, 15 분 간격으로 완충액을 교체 하면서 60 분간 평형 화시켰다. 시료들은 주입한 후 수축활성을 physiograph로 측 정하였다.

\section{메추리의 직장(rectum)에 대한 수축활성}

메추리 직장의 표본을 만들기 위해 항문 위쪽에서 가슴까지 절개하였다. 그 후 항문에서부터 $0.5 \mathrm{~cm}$ 떨어진 부위를 3-4 $\mathrm{cm}$ 길이로 재빨리 적출하였다. 적출한 직장은 결체조직을 제 거하고, $10-15 \mathrm{~mm}$ 정도의 단편을 만들어 $2 \mathrm{ml}$ 반응조에 고정 시켰다. 모든 과정은 Ringer 용액 하에서 행하였으며, 조성은 다음과 같다: $(\mathrm{mM}) \mathrm{NaCl} 187, \mathrm{KCl} 5.6, \mathrm{CaCl}_{2} \cdot 2 \mathrm{H}_{2} \mathrm{O}$ 2.2, Glucose 1.1, Hepes- $\mathrm{NaOH}$ (pH 7.4) 10. 적출한 직장을 반응조 의 아래쪽에 고정시키고 위쪽은 physiography system의 isometric transducer에 연결하여 $2.0 \mathrm{~g}$ 의 장력을 준 뒤 15 분 간격 으로 완충액을 교체하면서 60 분간 평형화시켰다. 시료들은 주 입한 후 수축활성을 physiograph로 측정하였다.

\section{귀뚜라미(Gryllidae bimaculatas)의 소낭에 대한 수축활성}

귀뚜라미의 배 쪽을 메스를 이용하여 절개한 후 식도아래에 위치한 소낭을 적출한다. 적출한 소낭은 결체 조직을 제거한 후 $7 \mathrm{~mm}$ 정도의 단편으로 만들었다. 모든 과정은 buffer 하에 서 행하였으며, 조성은 다음과 같다: $(\mathrm{mM}) \mathrm{NaCl} 128.34, \mathrm{KCl}$ 4.69, $\mathrm{CaCl}_{2} 1.89$, glucose 10 and $0.5 \mathrm{M}$ Tris- $\mathrm{HCl}$ (pH7.8) 5 . 이후 과정은 먹장어의 장관에 대한 수축활성의 측정법과 동일 하게 행하였다. 


\section{통계처리}

$\mathrm{ABRM}$ 의 반복적인 전기자극에 대한 조절활성은 control에 대한 약물반응의 크기를 \%로 나타냈다. 장관수축활성은 Ach 에 의한 수축반응을 $100 \%$ 로 하여 상대적 수치 \%로서 나타냈 으며, 근육 이완 활성은 Ach에 의한 최대수축에 대한 상대적 이완 \%로서 나타냈다. 통계적 처리는 student's t- test로서 했 다. 모든 반응 값은 means \pm S.E.로 표시했다.

\section{펩타이드의 합성 및 정제}

이전에 보고된 Fmoc-법을 사용하여 고상법으로 펩타이드 를 합성하였으며[33], C-말단이 amide인 형태의 펩타이드를 합성하기 위해 Fmoc-NH-PAL-resin을 사용하였다. 우선 $\mathrm{DMF}$ 로 resin을 팽윤시킨 후, $20 \%$ piperidine/DMF를 이용하 여 resin으로부터 Fmoc-보호기를 절단하였다. DIPCI/HOBT 법을 이용하여 결합시키고자 하는 아미노산의 카르복실기를 에스테르 형태로 활성화시켜, $\mathrm{NH}_{2}$-PAL-resin과 반응시켰다. 첫 번째 반응이 완료된 수지는 $\mathrm{DMF}$ 로 세정하고, 다시 $20 \%$ piperidine/DMF로, 첫 번째로 도입된 아미노산의 Fmoc-기를 절단하였다. 반응 후, $\mathrm{DMF}$ 로 세정하고 두 번째 아미노산을 $\mathrm{DIPCI} / \mathrm{HOBT}$ 법으로 결합시켰다. 이와 같은 과정을 순차적으 로 반복하여, 완전한 peptide 사슬을 resin에 성장시켰다. 각 단계에서 축합 반응 후, $20 \%$ piperidine/DMF에 의해 절단되 는 Fmoc-group은 UV 흡광도를 관찰하여 축합 반응의 여부를 결정하였다. Table 2에 각 아미노산의 축합 단계에 필요한 조 작과정을 나타내었다. 합성 펩타이드에 연결되어 있는 resin과 side chain의 보호기를 제거하기 위해서 절단시약인 TFA (5 $\mathrm{ml})$ : $m$-cresol $(0.6 \mathrm{ml})$ : thioanisole $(1.7 \mathrm{ml})$ : EDT $(0.9 \mathrm{ml})$ 을 사용하여 실온에서 90 분간 반응을 시켰다. 반응 후, resin을 여과한 다음 펩타이드 용액을 진공 농축하였으며 계속해서
농축액에 차가운 에테르를 첨가하여 peptide를 결정화시켰다. 합성한 펩타이드들은 $\mu$-Bondapak $\mathrm{C}_{18}(7.8 \times 300 \mathrm{~mm})$ column 을 사용하여 다음과 같은 조건으로 정제하였다: $\mathrm{A}$ 용매; $0.1 \%$ $\mathrm{TFA}$ 를 포함하는 $\mathrm{H}_{2} \mathrm{O}, \mathrm{B}$ 용매; $0.1 \% \mathrm{TFA}$ 를 포함하는 $\mathrm{CH}_{3} \mathrm{CN}$, $\mathrm{B}$ 용매의 gradient: $5 \rightarrow 65 \%$ (40 min), 유속; $2.0 \mathrm{ml} / \mathrm{min}$, 파장; $220 \mathrm{~nm}$. 부분 정제된 합성 펩타이드들의 최종정제를 하기 위 해 isocratic 용출방법을 사용하여 Spherisorb ODS2 $\mathrm{C}_{18}$ $(4.0 \times 125 \mathrm{~mm})$ column으로 정제하였다.

\section{합성 펩타이드들의 분자량 측정}

MALDI-TOF-MASS Spectrometer (Voyager-DE ${ }^{\mathrm{TM}}$ PRO, Perseptive Biosystems사, U.S.A.)를 이용하여 합성 펩타이드 들의 분자량을 측정하였다.

\section{결과 및 고찰}

\section{Myomodulin A (MMA)와 유도체들의 합성 및 정제}

군소로부터 정제한 $\mathrm{MMA}$ 의 구조와 활성간의 상관관계를 알아보기 위해 $\mathrm{MMA}$ 와 $\mathrm{N}$-말단에 존재하는 아미노산을 각각 하나씩 제거한 3 가지의 유도체를 합성하였고, $\mathrm{MMA}$ 와 활성을 비교하기 위하여 $\mathrm{MME}$ 도 합성하였다. 합성 $\mathrm{MMA}$ 와 유도체들 및 $\mathrm{MME}$ 를 정제하기 위해 semi-preparative $\mu$-Bondapak $\mathrm{C}_{18}$ $(7.8 \times 300 \mathrm{~mm})$ column을 사용하였다. 최종적으로 합성물들은 Spherisorb ODS2 $(4.0 \times 125 \mathrm{~mm})$ column을 사용하여 정제하 였으며, $\mathrm{MMA}$ 는 $27 \%$ 그리고 유도체 및 $\mathrm{MME}$ 는 $28 \%$ 의 isocratic 조건으로 각각 분리하였다. 최종 정제한 합성물들의 수 율은 약 30-32\%이다. Table 3에 합성한 물질들의 일차구조, 분자량 및 retention time (RT)을 나타내었다. 그리고, 합성 펩 타이드들의 분자량은 MALDI-TOF- Mass를 이용하여 확인한

Table 2. Program for solid-phase peptide synthesis

\begin{tabular}{|c|c|c|c|}
\hline Step & Reagent & Operation & Mix time $/ \mathrm{min}$ \\
\hline 1 & DMF & $3 \times$ Washing & 3 \\
\hline 2 & $20 \%$ piperidine/DMF & $\begin{array}{l}2 \times \text { Deprotection } \\
1 \times \text { Deprotection }\end{array}$ & $\begin{array}{c}3 \\
20\end{array}$ \\
\hline 3 & DMF & 6×Washing & 1 \\
\hline 4 & $\begin{array}{c}\text { Fmoc-amino acid } \\
\text { HOBt/DMF and DIPCI in DMF }\end{array}$ & Coupling & 90 \\
\hline 5 & DMF & $3 \times$ Washing & 1 \\
\hline
\end{tabular}

Table 3. Primary structure, molecular weight and retention time of MMA, its analogues and MME

\begin{tabular}{llcc}
\hline Peptides & Sequence & Mass (m/z) & RT (min) \\
\hline Myomodulin A & Pro-Met-Ser-Met-Leu-Arg-Leu-amide & 847.41 & 12 \\
Des[Pro']-MMA & Met-Ser-Met-Leu-Arg-Leu-amide & 750.15 & 10 \\
Des[Pro', Met']-MMA & Ser-Met-Leu-Arg-Leu-amide & 618.85 & 6 \\
Des[Pro', Met', Ser ${ }^{2}$ ]-MMA & Met-Leu-Arg-Leu-amide & 532.03 & 4.5 \\
Myomodulin E & Gly-Leu-Gln-Met-Leu-Arg-Leu-amide & 830.50 & 13 \\
\hline
\end{tabular}


결과, 모든 화합물들의 이론값과 측정값은 일치하였다: $\mathrm{MMA}$, $\mathrm{C}_{36} \mathrm{H}_{67} \mathrm{O}_{8} \mathrm{~N}_{11} \mathrm{~S}_{2}$ 846.04， $[\mathrm{M}+\mathrm{H}]^{+}$847.41; Des[Pro $\left.{ }^{1}\right]$-MMA, $\mathrm{C}_{31} \mathrm{H}_{60} \mathrm{O}_{7} \mathrm{~N}_{10} \mathrm{~S}_{2}$ 748.93, $[\mathrm{M}+\mathrm{H}]^{+}$750.15; Des[Pro ${ }^{1}$, Met ${ }^{2}$ ]-MMA, $\mathrm{C}_{26} \mathrm{H}_{51} \mathrm{O}_{6} \mathrm{~N}_{9} \mathrm{~S}$ 617.74, $[\mathrm{M}+\mathrm{H}]^{+}$618.85; Des[Pro ${ }^{1}, \mathrm{Met}^{2}$, Ser ${ }^{3}$-MMA, $\mathrm{C}_{23} \mathrm{H}_{46} \mathrm{O}_{4} \mathrm{~N}_{8} \mathrm{~S}$ 530.67, $[\mathrm{M}+\mathrm{H}]^{+}$532.03; MME, $\mathrm{C}_{36} \mathrm{H}_{68} \mathrm{O}_{8} \mathrm{~N}_{12} \mathrm{~S}$ 829.00, $[\mathrm{M}+\mathrm{H}]^{+} 830.50$.

진주담치 $\mathrm{ABRM}$ 의 전기자극에 의한 $\mathrm{MMA}$ 의 phasic contraction 활성

다양한 신경성 펩타이드의 분리와 특성 확인을 위한 bioassay system으로 많은 연구자들이 진주담치의 $\mathrm{ABRM}$ 을 이 용하고 있다. 또한 신경성 펩타이드들의 섭식 및 생식과의 연 관성을 확인하기 위해 $\mathrm{ABRM}$ 이외에도 연체동물의 소화기관 인 소낭 및 penial retractor muscle도 널리 이용되고 있다. 우 선 진주담치의 $\mathrm{ABRM}$ 은 두 가지 수축 형태인, 전기자극에 의 한 phasic contraction과 catch contraction을 뚜렷하게 나타내 고 있기 때문에[32], $\mathrm{ABRM}$ 의 조절 활성을 알아보기 위해서 본 연구에서 합성한 $\mathrm{MMA}$ 및 $\mathrm{MME}$ 를 사용하여 농도별로 phasic contraction 활성을 측정하였다. Fig. 1에 MMA 및 $\mathrm{MME}$ 의 phasic contraction활성 결과를 나타내었다. MMA의 phasic contraction을 촉진하는 역치 농도는 $1 \times 10^{-8} \mathrm{M}$ 이었고, $1 \times 10^{-7} \mathrm{M}$ 까지 수축활성이 증가하였다. 그러나 흥미롭게도 $1 \times 10^{-6} \mathrm{M}$ 에서는 phasic contraction을 억제하였으며, $1 \times 10^{-5} \mathrm{M}$ 에서는 phasic contraction을 완전하게 억제하는 것으로 나타 났다. 그러나 $\mathrm{MME}$ 는 $\mathrm{MMA}$ 와는 다르게 농도가 증가할수록 phasic contraction을 억제하였다. Mytilis의 pedal ganglia로 부터 MMA와 유사한 일차구조를 나타내는 catch-relaxing peptide (CARP)가 발견되었으며, 일차구조는 Ala-Met-Pro-
Met-Leu-Arg-Leu-NH $\mathrm{H}_{2}$ 이다[20]. CARP도 MMA와 마찬가지 로 phasic contraction을 나타낸다고 보고되었다. 이와는 반대 로 $\mathrm{MME}$ 는 phasic contraction을 억제하였다. 이러한 이유는 이들 3종류의 물질이 동일한 C-말단 영역을 가지고 있음에도 불구하고 $\mathrm{MMA}$ 와 CARP만이 $\mathrm{N}$-말단의 2번째 잔기에 Met이 공통으로 존재하기 때문에 이들 물질들은 유사한 반응을 나타 내었다고 생각된다. 따라서 $\mathrm{ABRM}$ 의 phasic contraction에 대 한 반응에는 $\mathrm{N}$-말단의 2 번째 잔기가 활성에 중요한 영향을 미치는 것으로 생각된다.

\section{진주담치 $\mathrm{ABRM}$ 의 catch-tension relaxation 활성}

$\mathrm{ABRM}$ 을 $1 \times 10^{-5} \mathrm{M}$ Ach으로 최대 수축시키는 catch-tension 상태를 만들어 합성물질들의 이완활성 작용을 조사하였다. Fig. 2는 ABRM의 catch-tension 상태에서 MMA 및 MME를 농도별로 누적투여하여 이완 활성을 측정한 결과이다. 그 결 과, $\mathrm{MMA}$ 는 $1 \times 10^{-8} \mathrm{M}$ 부터 활성이 확인되었고, 농도가 증가함 에 따라 이완활성도 함께 증가되었지만, 이들 두 물질간의 활 성차이가 관찰되었다. Hirata 등[18]에 의하면 CARP는 근육 의 postsynaptic site에 작용하여 catch-tension relaxing 활성 을 나타내었다. 마찬가지로MMA에 의한 $\mathrm{ABRM}$ 의 catchtension 이완 활성도 CARP와 유사한 작용에 의해 일어난 것 으로 추정할 수 있다. MMA의 유도체들 및 $\mathrm{MME}$ 를 누적 투여 한 결과, $\operatorname{Des}\left[\mathrm{Pro}^{1}\right]-\mathrm{MMA}$ 와 $\operatorname{Des}\left[\mathrm{Pro}^{1}, \mathrm{Met}^{2}\right]-\mathrm{MMA}$ 의 이완 활 성의 크기는 서로 비슷하였지만, $\mathrm{N}$-말단의 아미노산을 3 개 제 거한 $\operatorname{Des}\left[\mathrm{Pro}^{1}, \mathrm{Met}^{2}, \mathrm{Ser}^{3}\right]-\mathrm{MMA}$ 는 사용한 농도에서 이완 활 성이 나타나지 않았다(Fig. 3). MMA의 $\mathrm{ED}_{50}$ 값은 $6.6 \times 10^{-7} \mathrm{M}$ 이며, $\operatorname{Des}\left[\operatorname{Pro}^{1}\right]-\mathrm{MMA}$ 는 $2.9 \times 10^{-6} \mathrm{M}, \operatorname{Des}\left[\mathrm{Pro}^{1}, \mathrm{Met}^{2}\right]-\mathrm{MMA}$ 는 $4.5 \times 10^{-6} \mathrm{M}$ 이었다. $\mathrm{MME}$ 의 $\mathrm{ED}_{50}$ 값은 $5.8 \times 10^{-8} \mathrm{M}$ 이었다. 유도

\section{A. Myomodulin A}

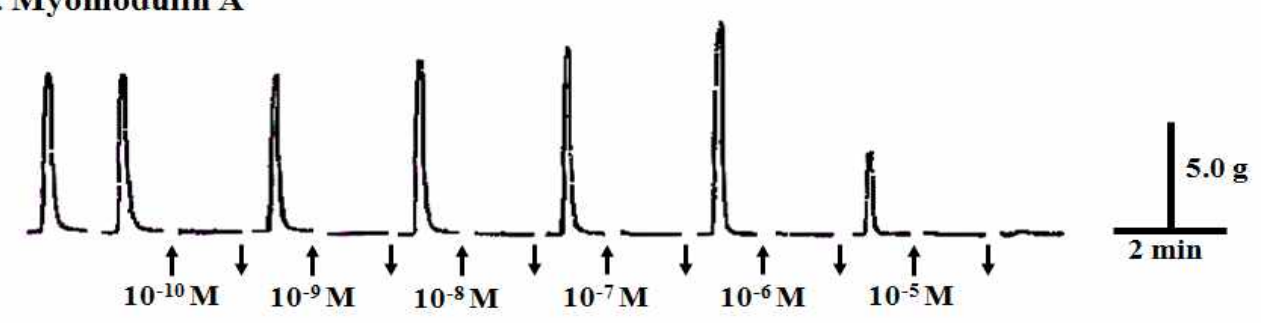

B. Myomodulin E

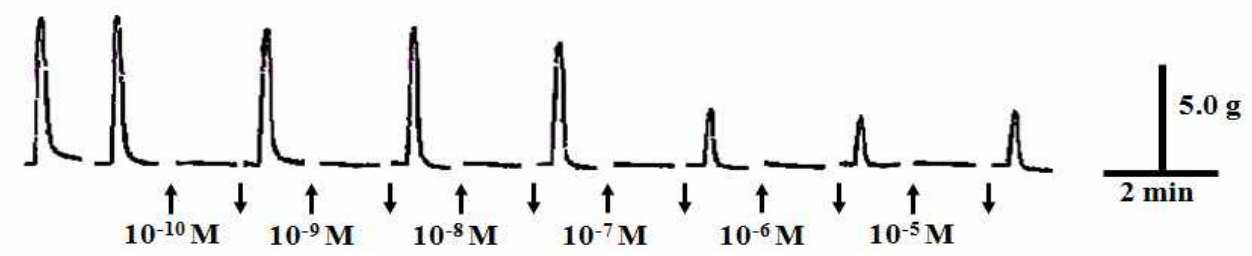

Fig. 1. Effects of myomodulin A (A) and E (B) on the phasic contractionin response to the respective electrical stimulation (23V, $50 \mathrm{~Hz}, 3 \mathrm{mec})$ of ABRM of M. edulis. 


\section{A. Myomodulin A}
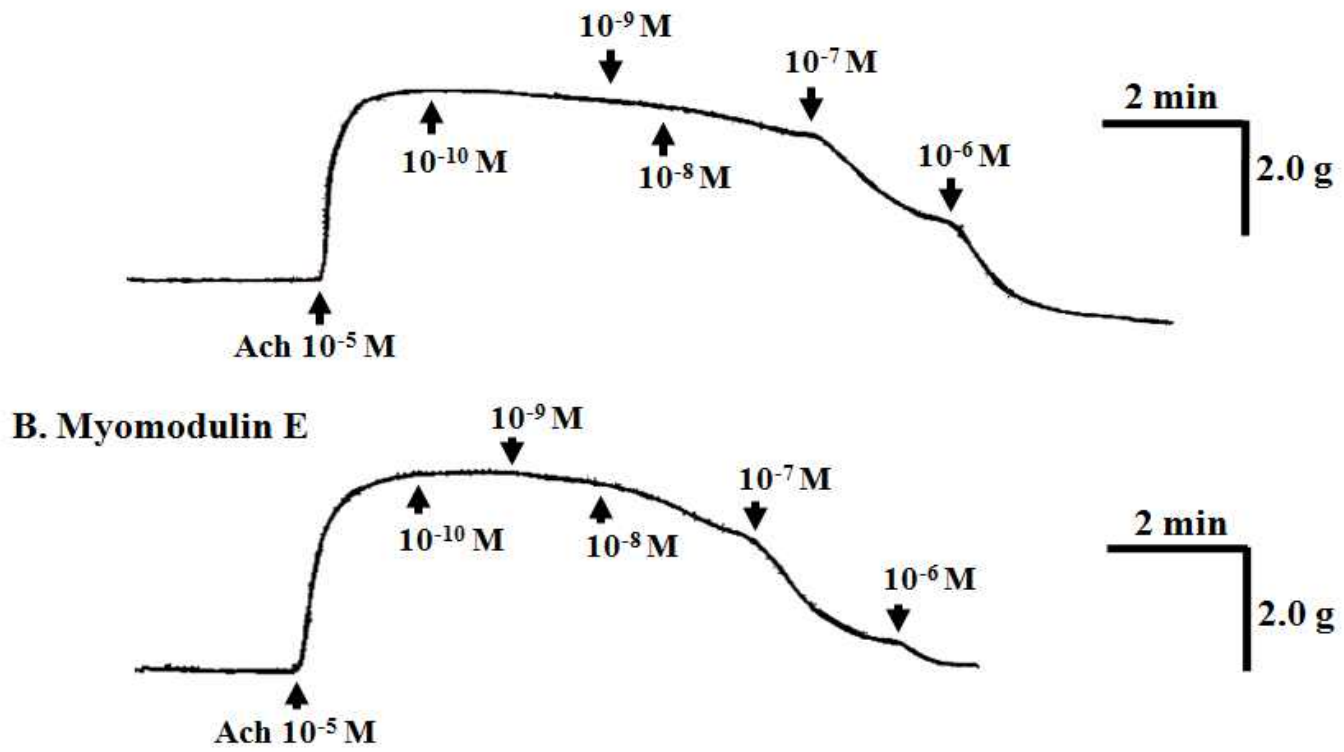

Fig. 2. The catch-relaxing response of myomodulin A (A) and E (B) on the ABRM of the M. edulis.

체들은 $\mathrm{MMA}$ 보다 $\mathrm{ED}_{50}$ 값이 약 4.4 배에서 6.6배 높았다. 그리 고, MMA는 MME보다 catch-tension relaxation 활성의 $\mathrm{ED}_{50}$ 값이 낮은 것으로 미루어 보아 $\mathrm{N}$-말단 아미노산 잔기들이 활 성에 중요한 역할을 하는 것으로 생각된다. 이들 펩타이드의 $\mathrm{E}_{\max }$ 값의 세기는 다음과 같다: $\mathrm{MME}>>\mathrm{MMA}>\operatorname{Des}\left[\mathrm{Pro}^{1}\right]-$

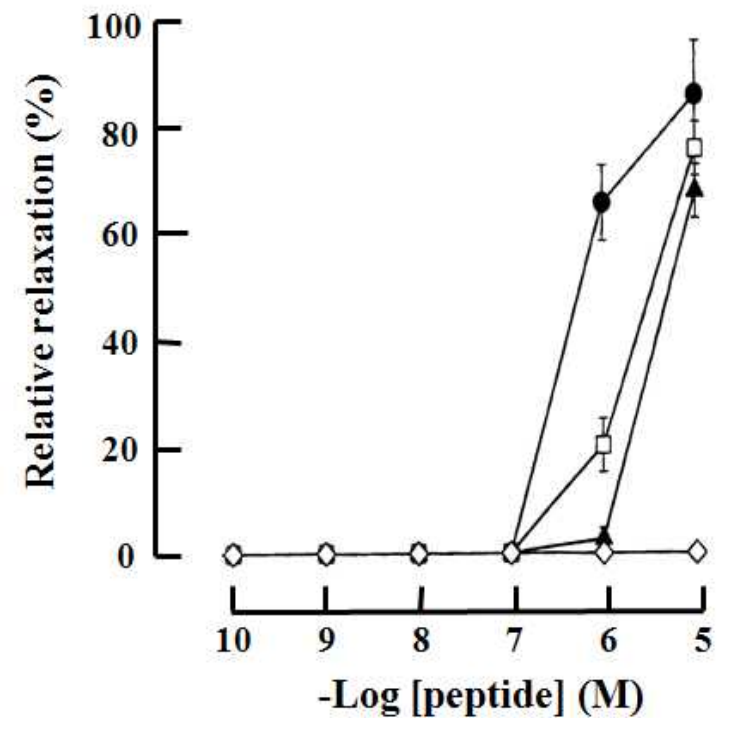

Fig. 3. The dose-dependent curve of myomodulin $\mathrm{A}$ and its analogues of catch-relaxing response $(n=4)$ on the ABRM of the $M$. edulis, MMA (O), Des[Pro $\left.{ }^{1}\right]-M M A$ $(\square)$, Des $\left[\operatorname{Pro}^{1}, \operatorname{Met}^{2}\right]-\operatorname{MMA}(\mathbf{\Delta})$, and $\operatorname{Des}\left[\operatorname{Pro}^{1}, \operatorname{Met}^{2}\right.$, Ser $\left.^{3}\right]$-MMA $(\diamond)$.
$\mathrm{MMA} \geq \operatorname{Des}\left[\mathrm{Pro}^{1}, \mathrm{Met}^{2}\right]-\mathrm{MMA}$. 이와 같이 MMA의 $\mathrm{N}$-말단에 존재하는 아미노산을 제거할수록 활성이 감소하는 현상을 보 였으며, 이러한 현상은 FMRFamide의 RFamide [25], MIP의 FVamide [16]에서도 발견되었다. 따라서 이러한 결과는 $\mathrm{MMA}$ 가 $\mathrm{ABRM}$ 의 $\mathrm{Ach}$ 에 의한 catch-tension의 이완 활성을 나타내기 위해서 C-말단에 존재하는 MLRLamide가 최소한으 로 필요한 동시에 $\mathrm{N}$-말단영역이 활성에 있어서 중요한 역할을 하고 있다는 것을 제시하고 있다.

\section{달팽이 소낭에 대한 수축 활성}

달팽이(A fulica)의 소낭에 대해 $\mathrm{MMA}$ 및 $\mathrm{MME}$ 를 농도별로 누적 적용하여 그 수축 활성 정도를 측정하였다(Fig. 4). MMA 및 $\mathrm{MME}$ 는 $1 \times 10^{-8} \mathrm{M}$ 부터 약간의 수축활성을 나타내기 시작하 였고, $1 \times 10^{-7} \mathrm{M}$ 에서 더 높은 농도로 갈수록 수축활성이 증가하 였다. A fulica의 소화기관인 소낭에 대해 수축반응이 있는 것 으로 보아 MMA는 소화작용에 관여하는 신경성 펩타이드라 생각된다. 특히, $\mathrm{MMA}$ 는 섭식행동의 과정에 관여하는 물질이 라고 알려져 있기 때문에[6,11], 본 연구 결과와 이들의 연구 결과는 잘 일치한다는 것을 의미한다. Fig. 5 및 Table 4 는 $\mathrm{MMA}$ 와 유도체, 그리고 $\mathrm{MME}$ 에 대한 농도별 반응곡선 및 이 들의 $\mathrm{ED}_{50}$ 과 $\mathrm{E}_{\max }$ 값을 나타낸다. $\mathrm{Des}\left[\mathrm{Pro}^{1}\right]-\mathrm{MMA}$ 의 활성은 $\mathrm{MMA}$ 와 마찬가지로 수축 활성이 유지되었다. 그러나 $\operatorname{Des}\left[\mathrm{Pro}^{1}, \mathrm{Met}^{2}\right]-\mathrm{MMA}$ 과 $\operatorname{Des}\left[\mathrm{Pro}^{1}, \mathrm{Met}^{2}, \mathrm{Ser}^{3}\right]-\mathrm{MMA}$ 는 수축 활성이 대부분 소실되거나 활성이 없는 것으로 확인되었다. $\mathrm{MMA}$ 와 Des[Pro $\left.{ }^{1}\right]-\mathrm{MMA}$ 의 이완 활성의 크기는 $\mathrm{ED}_{50}$ 과 $\mathrm{E}_{\max }$ 값에서 서로 비슷하였다. $\mathrm{MMA}$ 의 $\mathrm{ED}_{50}$ 값은 $8.0 \times 10^{-7} \mathrm{M}$ 이며, 


\section{A. Myomodulin A}
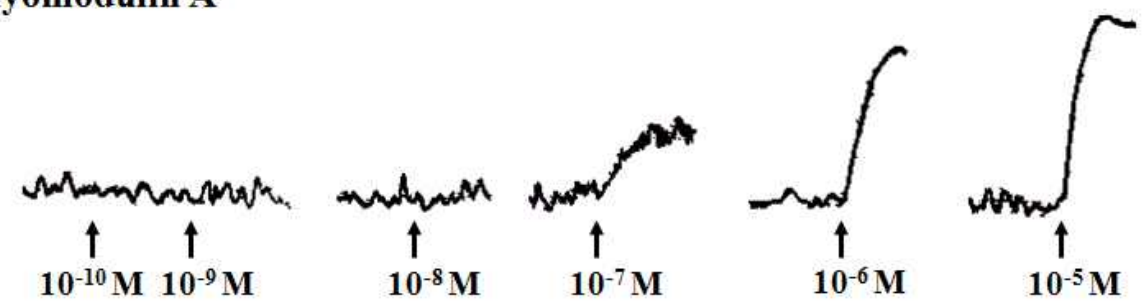
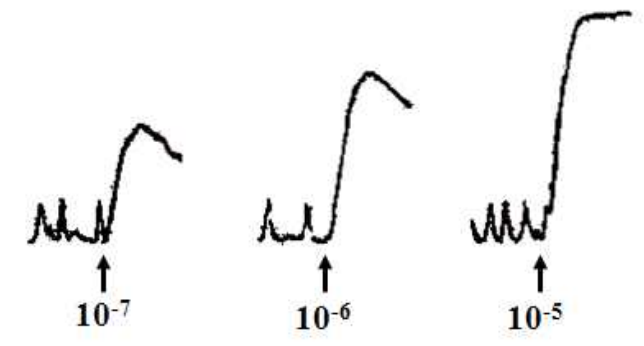
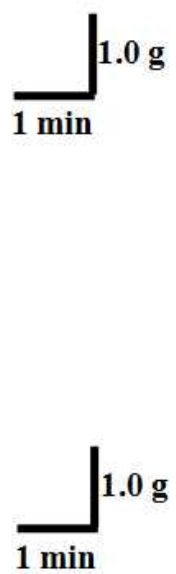

Fig. 4. The contractile response of myomodulin A (A) and E (B) on the crop of the African giant snail, Achatina fulica.

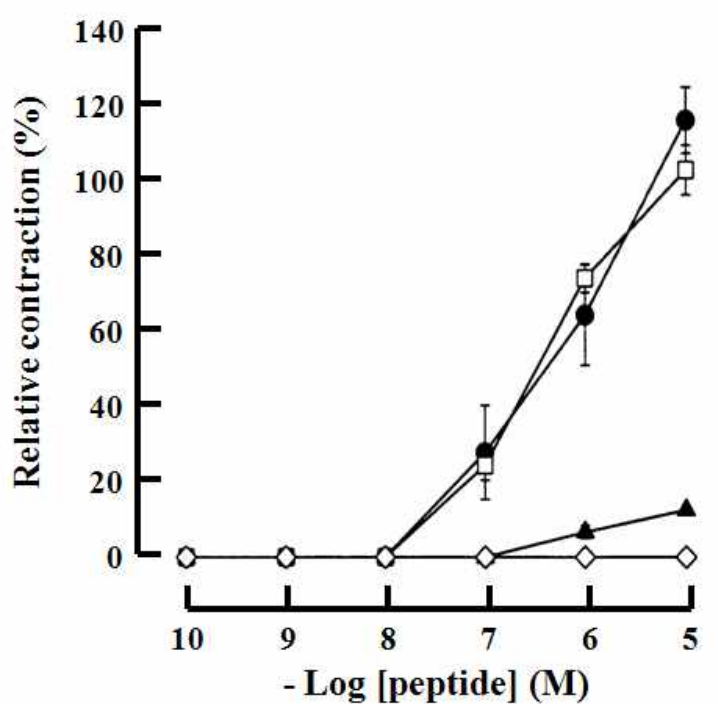

Fig. 5. The dose-dependent curve of myomodulin A and its analogues of catch-relaxing response $(n=4)$ on the crop of the African giant snail, A. fulica, MMA (O), $\operatorname{Des}\left[\operatorname{Pro}^{1}\right]$-MMA $(\square)$, Des[Pro $\left.{ }^{1}, \operatorname{Met}^{2}\right]$-MMA $(\mathbf{\Delta})$, and Des[Pro ${ }^{1}$, Met $^{2}$, Ser $\left.^{3}\right]-M M A(\diamond)$.

$\operatorname{Des}\left[\mathrm{Pro}^{1}\right]-\mathrm{MMA}$ 는 $6.4 \times 10^{-7} \mathrm{M}$, 및 $\mathrm{MME}$ 는 $5.0 \times 10^{-7} \mathrm{M}$ 이었 다. 이들 펩타이드의 $\mathrm{E}_{\max }$ 값의 세기는 다음과 같다: $\mathrm{MME}>$ MMA $\geq \operatorname{Des}\left[\right.$ Pro $\left.^{1}\right]-M M A ~ \gg \operatorname{Des}\left[\operatorname{Pro}^{1}\right.$, Met $\left.^{2}\right]-M M A \geq$ $\operatorname{Des}\left[\mathrm{Pro}^{1}, \mathrm{Met}^{2}, \mathrm{Ser}^{3}\right]-\mathrm{MMA}$. N-말단으로부터 2개의 잔기를 제거한 유도체에서는 활성이 완전히 소실되었지만, 첫 번째 잔기인 Pro만을 제거한 유도체는 활성이 유지되었다. 따라서 이러한 결과는 달팽이 소낭의 수축 활성에 있어서 $\mathrm{MMA}$ 의 첫 번째 잔기인 Pro은 반드시 필요한 잔기가 아니며 두 번째
잔기인 Met이 활성 유지에 매우 중요한 역할을 하고 있다는 것을 제시한다.

\section{달팽이 penial retractor muscle에 대한 이완 활성}

Penial retractor muscle을 $1 \times 10^{-5} \mathrm{M}$ 의 Ach으로 catch-tension 상태를 만든 후, $\mathrm{MMA}$ 및 $\mathrm{MME}$ 를 농도별로 투여하였다 (Fig. 6). MMA와 MME는 penial retractor muscle에 대해 1 $\times 10^{-7} \mathrm{M}$ 부터 이완 활성을 보였으며, 농도증가와 함께 이완 활성이 증가하는 것으로 나타났다. $\mathrm{Li}$ 등[26]에 의하면 $\mathrm{MMA}$ 는 Lymnaea의 penial retractor muscle에 대해서도 이완반응을 나타내었다. Fig. 7 및 Table 5는 MMA와 유도체, 그리고 $\mathrm{MME}$ 에 대해 이완활성을 측정한 농도 곡선 및 이들의 $\mathrm{ED}_{50}$ 값과 $\mathrm{E}_{\max }$ 값을 나타낸다. $\mathrm{MMA}$ 의 유도체들의 경우, $\mathrm{N}$-말단의 잔기 를 하나씩 제거함에 따라 이완 활성의 크기도 같이 감소하는 것으로 나타났다. 비록 $\mathrm{MMA}$ 와 $\operatorname{Des}\left[\mathrm{Pro}^{1}\right]-\mathrm{MMA}$ 는 최대이완 활성의 세기는 유사했지만, $\mathrm{MMA}$ 의 $\mathrm{ED}_{50}$ 활성 값은 $\operatorname{Des}\left[\operatorname{Pro}^{1}\right]$-MMA보다 약 8 배 낮았다. 그러나 $\mathrm{N}$-말단의 2개의 잔기들을 제거한 $\mathrm{Des}\left[\mathrm{Pro}^{1}, \mathrm{Met}^{2}\right]-\mathrm{MMA}$ 는 급격하게 활성이 감소되었다. 이러한 결과들로부터 penial retractor muscle의 이완활성을 유지하기 위해서는 crop에 대한 활성과 마찬가지 로 반드시 첫 번째 잔기의 Pro을 필요로 하지는 않지만, $\mathrm{N}$-말 단의 2번째 아미노산인 Met은 활성에 중요한 역할을 하는 것 으로 생각된다. 한편 $\mathrm{MME}$ 의 최대이완활성의 세기는 $\mathrm{MMA}$ 와 유사하였다. 흥미롭게도 $\operatorname{Des}\left[\mathrm{Pro}^{1}, \mathrm{Met}^{2}, \mathrm{Ser}^{3}\right]-\mathrm{MMA}$ 는 고농도 에서 $\mathrm{ABRM}$ 과 달팽이의 소낭에 대해서 활성이 다소 유지되었 다. 이들 펩타이드의 $\mathrm{E}_{\max }$ 값의 세기는 다음과 같다: $\mathrm{MME}>$ MMA > Des[Pro $\left.{ }^{1}\right]-M M A>\operatorname{Des}\left[\right.$ Pro $\left.^{1}, \mathrm{Met}^{2}\right]-\mathrm{MMA}>$ $\operatorname{Des}\left[\mathrm{Pro}^{1}, \mathrm{Met}^{2}, \mathrm{Ser}^{3}\right]-\mathrm{MMA}$. 따라서 MMA의 C-말단의 공통영 
Table 4. $\mathrm{ED}_{50}$ and $\mathrm{E}_{\max }$ of MMA, its analogues and MME induced contraction in the $A$. fulica crop (n=4)

\begin{tabular}{|c|c|c|}
\hline \multirow{2}{*}{ Peptides } & \multicolumn{2}{|c|}{ A. fulica crop } \\
\hline & $\mathrm{ED}_{50}$ & $\mathrm{E}_{\max }$ \\
\hline Myomodulin A & $8.0 \times 10^{-7} \mathrm{M}$ & $116.40(8.70)^{*}$ \\
\hline Des[Pro $\left.{ }^{1}\right]-M M A$ & $6.4 \times 10^{-7} \mathrm{M}$ & $103.25(6.55)$ \\
\hline Des[Pro $\left.{ }^{1}, \mathrm{Met}^{2}\right]-\mathrm{MMA}$ & $1.0 \times 10^{-6} \mathrm{M}$ & $12.64(0.14)$ \\
\hline Des[Pro $\left.{ }^{1}, \mathrm{Met}^{2}, \mathrm{Ser}^{3}\right]-\mathrm{MMA}$ & - & - \\
\hline Myomodulin E & $5.0 \times 10^{-7} \mathrm{M}$ & $146.50(12.40)$ \\
\hline
\end{tabular}

*: Number in parentheses are standard error.

- : Not effect.

\section{A. Myomodulin A}

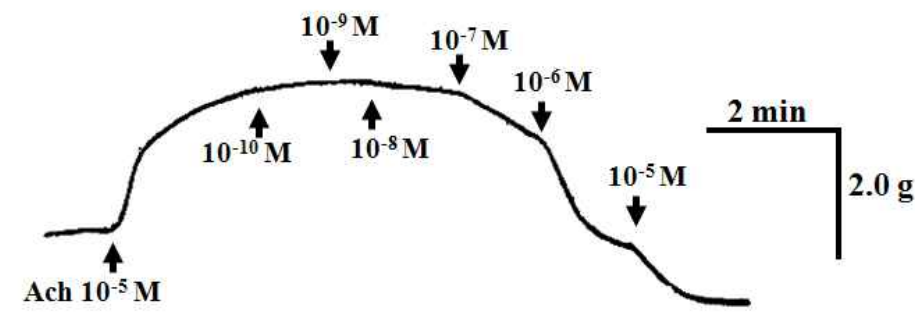

\section{B. Myomodulin E}
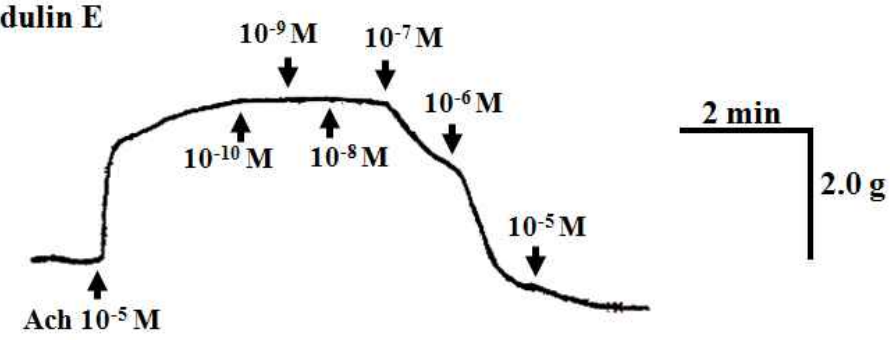

Fig. 6. The relaxing response of myomodulin A (A) and $\mathrm{E}(\mathrm{B})$ on the penial retractor muscle of the African snail, $A$. fulica.

역인 MLRLamide가 penical retractor muscle에 대해 최소한 의 활성을 나타내는 잔기인 것으로 사료된다(Fig. 7).

불가사리, 먹장어, 메추리, 귀뚜라미 muscle에 대한 활성 $\mathrm{MMA}$, 유도체 및 $\mathrm{MME}$ 는 이들 조직들에 대해 활성을 나타 내지 않았다(data not shown). 극피류, 원구류, 조류 및 곤충들 의 조직에 대해 $\mathrm{MMA}$ 및 $\mathrm{MME}$ 가 반응을 하지 않는 것으로 보아 이들 조직에 $\mathrm{MMs}$ 의 수용체가 존재하지 않는 것으로 여 겨진다.

결론적으로 $\mathrm{MMA}$ 는 유도체들에 비해 진주담치의 $\mathrm{ABRM}$, 달팽이의 crop 및 penial retractor muscle에 대해 높은 활성을 보였다. 그리고 $\mathrm{C}$-말단에 존재하는 4 개의 잔기들인 MLRLamide는 사용한 조직들에 대해 최소한의 활성을 유지 하기 위해 필요로 하는 영역인 것으로 생각된다. 이러한 결과 로 미루어 보아 $\mathrm{MMA}$ 의 $\mathrm{C}$-말단에 존재하는 공통영역인 MLRLamide가 활성을 나타내기 위해 receptor와 결합을 하는 데 있어서 중요한 인식부위인 것으로 예상되며, N-말단으로부 터 2번째까지의 잔기는 펩타이드의 안정성 또는 활성 특이성

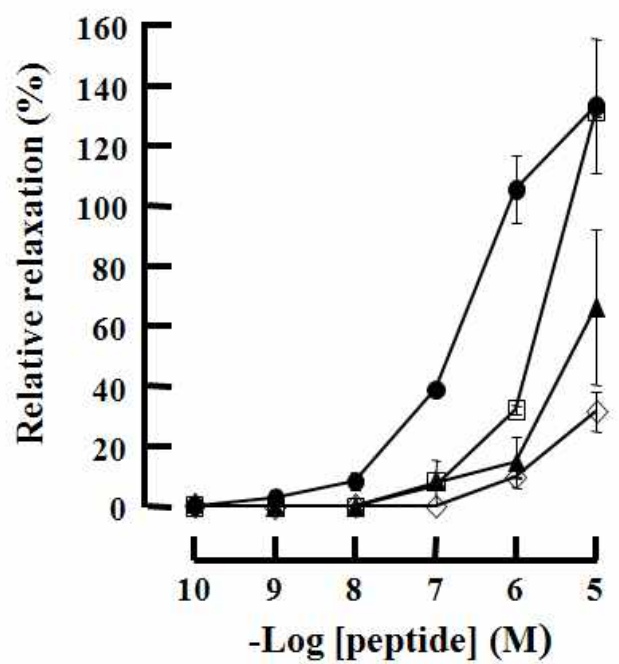

Fig. 7. The dose-dependent curve of myomodulin $\mathrm{A}$ and its ana$\operatorname{logs}$ of catch-relaxing response $(n=4)$ with the penial retractor muscle from the African giant snail, A. fulica. MMA (○), Des[Pro $\left.{ }^{1}\right]$-MMA ( $\left.\square\right)$, Des[Pro $\left.{ }^{1}, \operatorname{Met}^{2}\right]-M M A$ $(\mathbf{\Delta})$, and $\operatorname{Des}\left[\operatorname{Pro}^{1}, \mathrm{Met}^{2}, \operatorname{Ser}^{3}\right]-\mathrm{MMA}(\diamond)$. 
Table 5. $\mathrm{ED}_{50}$ and $\mathrm{E}_{\max }$ of MMA, its analogues and MME induced contraction in the A. fulica crop ( $\mathrm{n}=4$ )

\begin{tabular}{|c|c|c|}
\hline \multirow{2}{*}{ Peptides } & \multicolumn{2}{|c|}{ A. fulica penial retractor muscle } \\
\hline & $\mathrm{ED}_{50}$ & $\mathrm{E}_{\max }$ \\
\hline Myomodulin A & $4.0 \times 10^{-7} \mathrm{M}$ & $133.40(22.30)^{*}$ \\
\hline Des[Pro $\left.{ }^{1}\right]-M M A$ & $3.3 \times 10^{-6} \mathrm{M}$ & $131.65(1.65)$ \\
\hline Des[Pro' ${ }^{1}$, Met $\left.^{2}\right]-M M A$ & $3.3 \times 10^{-6} \mathrm{M}$ & $66.45(25.9)$ \\
\hline Des $\left[\right.$ Pro $^{1}$, Met $^{2}$, Ser $\left.^{3}\right]-M M A$ & $2.4 \times 10^{-6} \mathrm{M}$ & $31.55(6.55)$ \\
\hline Myomodulin E & $6.5 \times 10^{-7} \mathrm{M}$ & $148.30(16.60)$ \\
\hline
\end{tabular}

* : Number in parentheses are standard error.

에 관여한다고 여겨진다. 또한 MMA 및 유도체가 진주담치의 이동과 부착에 중요한 역할을 하는 $\mathrm{ABRM}$ 에 활성을 나타내 고, A. fulic의 소화기관인 소낭과 재생산에 관여하는 penial retractor muscle에 대해 각각 특유의 활성을 나타낸다는 것을 확인하였다. 따라서 MMA는 특히 연체동물에 있어서 각기 고 유의 기능을 가지는 3 종류의 다른 조직에 대해 이동, 섭식 및 생식작용에 관련된 복합적인 기능을 동시에 조절할 수 있는 중요한 신경전달물질이며 평활근 조절 기구에 관여하고 있다 는 것을 의미한다.

\section{감사의 글}

이 논문은 2008년도 부경대학교 연구년 교수 지원사업에 의하여 연구되었음(PS-2008-038)

\section{Reference}

1. Benarroch, E. E. 1994, Neuropeptides in the sympathetic system: Presence, plasticity, modulation and implications. Ann. Neurol. 36, 6-13.

2. Březina, V., B. Bank, E. C. Cropper, S. Rosen, F. S. Vilim, I. Kupfermann, and K. R. Weiss. 1995. Nine members of the myomodulin family of peptide cotransmitters at the Bl6-ARC neuromuscular junction of Aplysia. J. Neuophys. 74, 54-72.

3. Brown, R. E. 1994. An introduction to neuroendocrinology. ed. Cambridge University Press, London, U.K.

4. Christie, A. E., C. Hall, M. Oshinsky, and E. Marder. 1994. Buccalin-like and myomodulin-like peptides in the stomatogastric ganglion of the crab Cancer borealis. J. Exp. Biol. 193, 337-343.

5. Church, P. J. and P. E. Lloyd. 1991. Expression of diverse neuropeptide cotransmitters by identified motor neurons in Aplysia. J. Neurosci. 11, 618-625.

6. Cohen, J. L., K. R. Weiss, and I. Kupfermann. 1978. Motor control of buccal muscles in Aplysia. J, Neurophysiol. 41, 157-180.

7. Critz, S. D., D. A. Baxter, and J. H. Byrne. 1991. Modulatory effects of serotonin, FMRFamide, and myomodulin on the duration of action potentials, excitability, and membrane currents in tail sensory neurons of Aplysia. J. Neurophys. 66,
1912-1926.

8. Cropper, E. C., P. E. Lloyd, W. Reed, R. Tenenbaum, I. Kupfermann, and K. R. Weiss. 1987. Multiple neuropeptides in cholinergic motor neurons of Aplysia: evidence for modulation intrinsic to the motor circuit. Proc. Natl. Acad Sci. USA 84, 3486-3490.

9. Cropper, E. C., M. W. Miller, R. Tenenbaum, M. A. G. Kolks, I. Kupfermann, and K. R. Weiss. 1988. Structure and action of buccalin: a modulatory neuropeptide localized to an identified small cardioactive peptide containing cholinergic motor neuron of Aplysia californica. Proc. Natl. Acad Sci. USA 85, 6177-6181

10. Cropper, E. C., M. W. Miller, F. S. Vilim, R. Tenenbaum, I. Kupfermann, and K. R. Weiss. 1990. Buccalin is present in the cholinergic motor neuron B16 of Aplysia and it depresses accessory radula closer muscle contractions evoked by stimulation of B16. Brain Res. 512, 175-179.

11. Cropper, E. C., D. Price, R. Tenenbaum, I. Kupfermann, and K. R. Weiss. 1990. Release of peptide cotransmitters from a cholinergic motor neuron under physiological conditions. Proc. Natl. Acad Sci. USA 87. 933-937.

12. Cropper, E. C., R. Tenenbaum, M. A. G. Kolks, I. Kupfermann, and K. R. Weiss. 1987. Myomodulin : A bioactive neuropeptide present in an identified cholinergic buccal motor neuron of Aplysia. Proc. Natl. Acad Sci. USA 84, 5483-5486.

13. Cropper, E. C., F. S. Vilim, A. Alevizos, R. Tenenbaum, M. A. G. Kolks, S. Rosen, I. Kupfermann, and K. R. Weiss. 1991. Structure, bioactivity and cellular localization of myomodulin B: A novel Aplysia peptide. Peptides 12, 683-690.

14. Evans P. D. 1994 The effects of myomodulin and structurally related neuropeptides on skeletal neuromuscular transmission in the locust. J. Exp. Biol. 190, 253-264.

15. Feany, M. B. 1996. Neuropeptide modulation of learning and memory processes. Rev. Neurosci. 7, 151-164.

16. Fujisawa, Y., I. Kubota, T. Ikeda, H. Minakata, and Y. Muneoka. 1991. A variety of Mytilus inhibitory peptides in the ABRM of Mytilus edulis. Isolation and characterization. Comp. Biochem Physiol. 100C, 525-531.

17. Fujiwara-Sakata and M. Kobayashi. 1992. Neuropeptides regulate the cardiac activity of a prosobranch mollusc, Rapana thomasiana. Cell Tissue Res. 269, 241-247.

18. Greenberg, M. J., K. E. Doble, W. Lesser, T. D. Lee, N. A. Pennell, C. G. Morgan, and D. A. Price, 1997. Characterization of myomodulin-related peptides from the 
pulmonate snail Helix aspersa. Peptides 18, 1099-1106.

19. Hirata, T., I. Kubota, M. Imada, Y. Muneoka, and M. Kobayashi. 1989. Effects of the catch-relaxing peptide on molluscan muscles. Comp. Biochem Physiol. 92C, 283-288.

20. Hirata, T., I. Kubota, I. Takabatake, A. Kawahara, N. Shimamoto, and Y. Muneoka. 1987. Catch-relaxing peptide isolated from Mytilus pedal ganglia. Brain Res. 422, 374-376.

21. Ikeda, T., H. Minakata, T. Fujita, Y. Muneoke, T. Kiss, L. Hiripi, and K. Nomoto. 1993. Neuropeptides isolated from Helix pomatia, Part 1. Peptides related to MIP, buccalin, myomodulin-CARP and SCP. In: Yanaihara N., editor. Peptide chemistry 1992. Leiden, ESCOM, 576-578.

22. Kanda, T., Y. Kuroki, I. Kubota, Y. Muneoka, and M. Kobayashi. 1990. Neuropeptides isolated from the ganglia of a prosobranch mollusc, Fusinus ferrugineus. pp. 39-44 In Yanaihara N (ed.) Peptide chemistry 1989. Protein Research Foundation, Osaka.

23. Kim, C. H., H. J. Seo, E. Y. Hwang, E. J. Kim, H. J. Go, I. H. Kim, J. K. Seo, J. H. Moon, M. D. Huh, and N. G. Park. 2001. Purification of myomodulin A and myomodulin E from the central nervous system of the sea hare, Aplysia kurodai. J. Kor. Fish Soc. 34, 279-284.

24. Kobayashi, M. and Y. Muneoka. 1986. Structural requirements for FMRFamide-like activity on the heart of the prosobranch Rapana thomasiana. Comp. Biochem Physiol. 84C, 349-352.

25. Lesser, W., M. J. Greenberg, K. E. Doble, T. D. Lee, C. G. Morgan, N. A. Pennell, and D. A. Price. 1992. Isolation and characterization of myomodulin-CARP-related peptides (MCRPs) in molluscs. Soc. Neurosci. Abstr. 18, 469.

26. Li, K. W., F. A. Van Golen, J. Van Minnen, P. A. Van Veelen, J. Van der Greef, and W. P. M. Geraerts. 1994. Structural identification, neuronal synthesis, and role in male copulation of myomodulin-A of Lymnaea: a study involving direct peptide profiling of nervous tissue by mass spectrometry. Mol. Brain Res. 25, 355-358.

27. Lloyd, P. E., I. Kupfermann, and K. R. Weiss. 1984. Evidence for parallel actions of a molluscan neuropeptide and serotonin in mediating arousal in Aplysia. Proc. Natl. Acad Sci. USA 81, 2934-2937.

28. Lopez, V., L. Wickham, and L. Desgroseillers. 1993. Molecular cloning of myomodulin cDNA, a neuropeptide precursor gene expressed in neuron L10 of Aplysia californica. DNA Cell Biol. 12, 53-61.

29. Miller, M. W., A. Alevizos, E. C. Cropper, F. S. Vilim, D. Karagogeos, I. Kupfermann, and K. R. Weiss. 1991. Localization of myomodulin-like immunoreactivity in the central nervous system and peripheral tissues of Aplysia californica. J. Comp. Neurol. 314, 627-644.

30. Miller, M. W., S. Beushausen, A. Vitek, S. Stamm, I. Kupfermann, J. Brosius, and K. R. Weiss. 1993. The myomodulin-related neuropeptides: characterization of a gene encoding a family of peptide cotransmitters in Aplysia. J. Neurosci. 13, 3358-3367.

31. Miller, M. W., F. S. Vilim, E. C. Cropper, A. Alevizos, R. Tenenbaum, D. Karagogeos, I. Kupfermann, and K. R.
Weiss. 1990. Structure and distribution of myomodulin related neuropeptides in Aplysia. Soc. Neurosci. Abstr. 16, 307.

32. Muneoka, Y. and H. Saito. 1986. Pharmacology of FMRFamide in Mytilus catch muscle. Comp. Biochem Physiol. 85C, 207-214.

33. Park, N. G., Y. Yamato, S. Lee, and G. Sugihara. 1995. Interaction of mastoparan-B from venom of a hornet in Taiwan with phospholipid bilayers and its antimicrobial activity. Biopolymers 36, 793-801.

34. Puroux, J., A. Pedelaborde, and B. G. Loughton. 1993. The effect of proctolin analogues and other peptides on locust oviduct muscle contractions. Peptides 14, 1103-1109.

35. Richimond, J. E., A. G. M. Bulloch, and K. Lukowiak. 1986. Peptidergic modulation of a neuromuscular junction in Aplysia: bioactivity and immunocytochemistry. Brain Res. 370, 159-164.

36. Santama, N., M. Brierley, J. F. Burke, and P. R. Benjamin. 1994. Neural network controlling feeding in Lymnaea stagnalis: immunocytochemical localization of myomodulin, small cardioactive peptide, buccalin, and FMRFamide-related peptides. J. Comp. Neurol. 342, 352-365.

37. Santama, N., C. H. Wheeler, J. F. Burke, and P. R. Benjamin. 1994. Neuropeptides myomodulin, small cardioactive peptide, and buccalin in the central nervous system of Lymnaea stagnalis: purification, immunoreactivity, and artifacts. $J$. Comp. Neurol. 342, 335-351.

38. Shuttleworth, C. W. R. and K. D. Keef. 1995. Role of peptides in enteric neuromuscular transnission. Regul. Pept. 54, 101-120.

39. Swales, L. S. and P. D. Evans. 1994. Distribution of myomodulin-like immunoreactivity in the adult and developing ventral nervous system of the locust Schistocerca gregaria. J. Comp. Neurol. 343, 263-280.

40. Takahashi, T., O. Matsushima, F. Morishita, M. Fujimoto, T. Ikeda, H. Minakata, and K. Nomoto. 1994. A myomodulin-CARP related peptide isolated from a polychaete annelid, Perinereis vancaurica. Zool. Sci. 11, 33-38.

41. van Golen, F. A., K. W. Li, S. Chen, C. R. Jimenez, and W. P. M. Geraerts. 1996. Various isoforms of myomodulin identified from the male copulatory organ of Lymnaea show overlapping yet distinct modulatory effects on the penis muscle. J. Neurochem 66, 321-329.

42. Vilim, F. S. and E. Ziff. 1994. Antibodies to the Aplysia neuropeptide myomodulin stain varicose processes in rat brain. Soc. Neurosci. Abstr. 20, 515.

43. Wang, Y., D. A. Price and C. L. Sahley. 1998. Identification and Characterization of a myomodulin-like peptide in the leech. Peptides 19, 487 - 493.

44. Wang, Y., J. A. Strong, and C. L. Sahley. 1999. Modulatory effects of myomodulin on the excitability and membrane currents in retzius cells of the leech. J. Neurophysiol. 82, 216-225.

45 Zadina, J. E., W. A. Banks, and A. J. Kastin. 1986. Central nervous system effects of peptides, 1980-1985: A cross-listing of peptides and their central actions from the first six years of the journal peptides. Peptides 7, 497-537. 


\section{초록 : Myomodulin A 및 유도체들의 합성 및 생리활성}

\section{박남규*}

(부경대학교 수산과학대학 생물공학과)

군소인 Aplysia kurodai의 중추신경절로부터 정제된 myomodulin A (MMA)가 정제되었다. MMA의 일차구조 는 Pro-Met-Ser-Met-Leu-Arg-Leu-NH $\mathrm{N}_{2}$ 이며, 이 펩타이드는 다른 연체동물에서 발견된 myomodulin 계열의 펩타 이드와 같은 구조를 지닌다. 정제된 MMA는 Mytilus edulis의 anterior byssus retractor muscle (ABRM)에서 phasic contraction을 조절하는 것으로 나타났다. MMA의 구조와 활성간의 상관관계를 알아보기 위해서 $\mathrm{MMA}$, $\operatorname{Des}\left[\operatorname{Pro}^{1}\right]$-MMA, Des[$\left[\operatorname{Pro}^{1}, \mathrm{Met}^{2}\right]-\mathrm{MMA}, \operatorname{Des}\left[\operatorname{Pro}^{1}, \mathrm{Met}^{2}, \mathrm{Ser}^{3}\right]$-MMA 및 MME를 합성하였다. Des[$\left[\operatorname{Pro}^{1}\right]-\mathrm{MMA}$, $\operatorname{Des}\left[\operatorname{Pro}^{1}, \mathrm{Met}^{2}\right]$-MMA 및 $\operatorname{Des}\left[\mathrm{Pro}^{1}, \mathrm{Met}^{2}, \mathrm{Ser}^{3}\right]$-MMA의 일차구조는 각각 Met-Ser-Met-Leu-Arg-Leu-NH${ }_{2}$, SerMet-Leu-Arg-Leu- $\mathrm{NH}_{2}$ 및 Met-Leu-Arg-Leu- $\mathrm{NH}_{2}$ 이다. MMA 및 합성 물질들을 사용하여 ABRM 및 Achatinafulica의 소낭과 penial retractor muscle에 대해 활성을 측정하였다. MMA는 $1 \times 10^{-8} \mathrm{M}$ 또는 더 낮은 농도 에서 $\mathrm{ABRM}$ 의 수축활성을 증가시키는 것으로 나타났지만, $1 \times 10^{-8} \mathrm{M}$ 또는 고농도에서는 phasic contraction을 억 제하였다. MMA와 유도체들은 소낭에 대해서는 수축반응을 보였지만, penial retractor muscle에 대해서는 이완 활성을 나타내었다. 이러한 결과들은 MMA의 C-말단부위에 있는 Met-Leu-Arg-Leu- $\mathrm{NH}_{2}$ 가 ABRM의 수축반응 뿐만 아니라 연체동물의 생식기능 및 소화 활성을 조절하기 필요한 최소한의 구조라는 것을 나타낸다. 